\title{
A Correlative Study of an Iron-Base Superalloy Using Transmission Electron Microscopy and Atom Probe Tomography
}

\author{
D.J. Larson*, T.J. Prosa*, S.L.P. Kostrna*, M. Ali*, T.F. Kelly*, C. Stallybrass**, A. \\ Schneider**, G. Sauthoff** and J. Degas** \\ *Imago Scientific Instruments, 6300 Enterprise Ln, Suite 100, Madison, WI 53719, USA. \\ **Max-Plank-Institut für Eisenforschung GmbH, D-40074 Düsseldorf, Germany.
}

Many heat resistant ferritic steels have superior thermal expansion and conductivity properties compared to Ni-based alloys but are somewhat limited in their applications above $\sim 600^{\circ} \mathrm{C}$ by their mechanical properties. Efforts are being made to use precipitation strengthening to improve these properties and thus the efficiency of such alloys [1]. One such effort uses coherent (Ni,Fe)Al precipitates in a ferritic matrix, Fig. 1, and has shown good initial results. Transmission electron microscopy (TEM) has been used to understand globally the precipitate microstructure as it evolves with heat treatment. In order to understand the mechanisms by which such precipitation occurs, it is important to know how the composition variations in the structure on the scale of the precipitates evolve with heat treatment. Atom probe tomography (APT) [2] excels at such atomicscale characterization and is a strong complement to the imaging capabilities of TEM. The local electrode atom probe (LEAP) [3] has been used to characterize the nanoscale microstructure in this alloy in order to determine the chemistry of the third phase (yellow arrow) precipitated inside the $(\mathrm{Ni}, \mathrm{Fe}) \mathrm{Al} \mathrm{B} 2$ phase, which is shown as the darkly-imaging phase in Fig. 1b.

The Fe-18.1at.\% Ni-22.9at.\% Al-9.5at.\% Cr alloy was produced by vacuum induction melting followed by solution annealing at $1200^{\circ} \mathrm{C}$ with air cooling. For atom probe analysis, rods of this material were sharpened by electropolishing to have a radius of curvature of less than $100 \mathrm{~nm}$ at the apex. Three phases in the microstructure were identified consistent with prior work [1]. A primary Fe-rich phase (A2), a secondary NiAl phase (B2), and a third Fe-rich precipitate. Precipitates of the primary phase within the secondary phase were not seen to form within $\sim 15 \mathrm{~nm}$ of large scale primary regions, i.e., there is a denuded zone or precipitate free zone near the primary phase A2 phase.

Fig. 2 shows a LEAP analysis with a volume of (80x80x500) nm made up of 110 million atoms. On the right side of Fig. 2, two composition profiles are shown. The top one is across a narrow B2 region between two A2 regions showing the $\sim 50 / 50$ composition of the NiAl phase in this region. The lower profile reveals that the very small $(\sim 5 \mathrm{~nm})$ precipitates (yellow arrow in Fig. 1) inside the NiAl phase appear to be secondary Fe-rich phase. Through this correlative microscopy effort with TEM and APT, a greater understanding of the precipitation sequence and evolution of the microstructure is obtained.

\section{References}

[1] C. Stallybrass and G. Sauthoff, Mat. Sci. Eng. A, 387-389 (2004) 985.

[2] M.K. Miller, Atom Probe Tomography, Kluwar Academic Publishers, New York, 2000.

[3] T.F. Kelly and D.J. Larson, Mat. Char. 44 (2000) 59. 


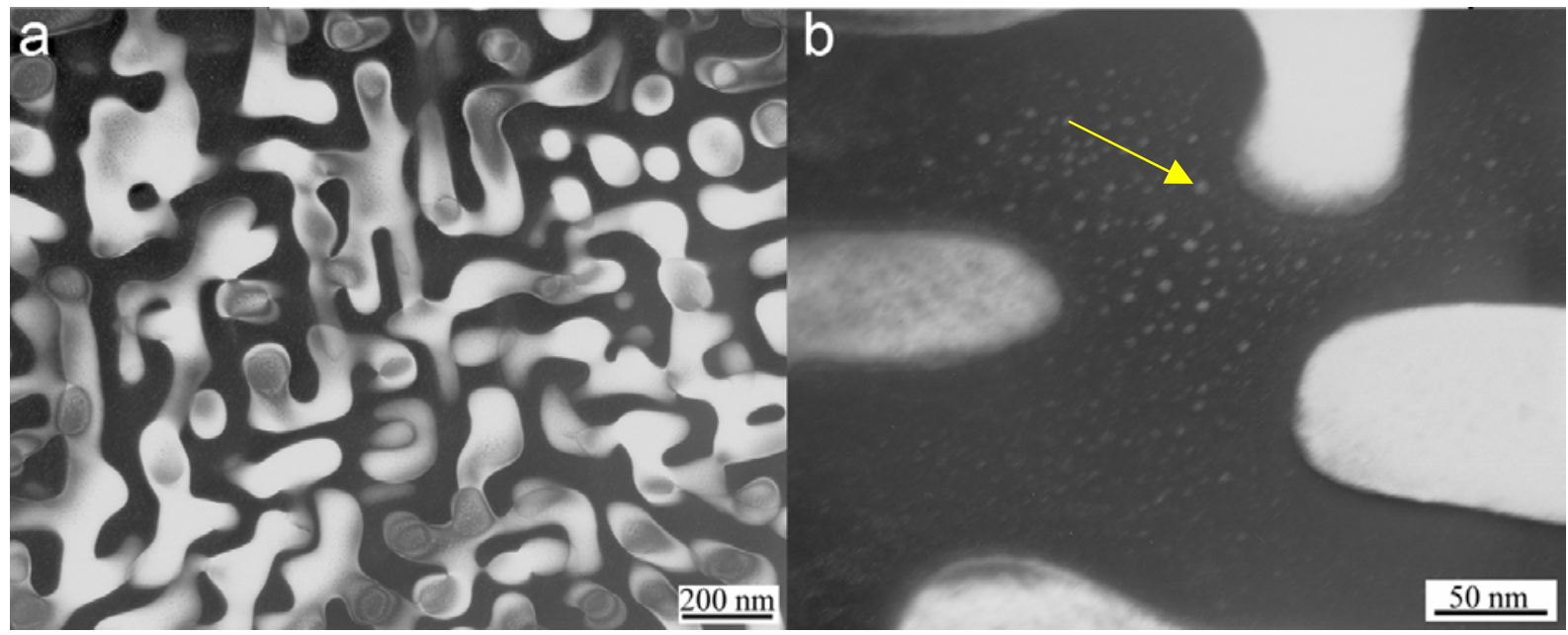

Fig. 1. TEM (dark field) images of Fe-Ni-Al-Cr alloy showing (a) an apparent two-phase microstructure at low magnification and (b) three phases at higher magnification.

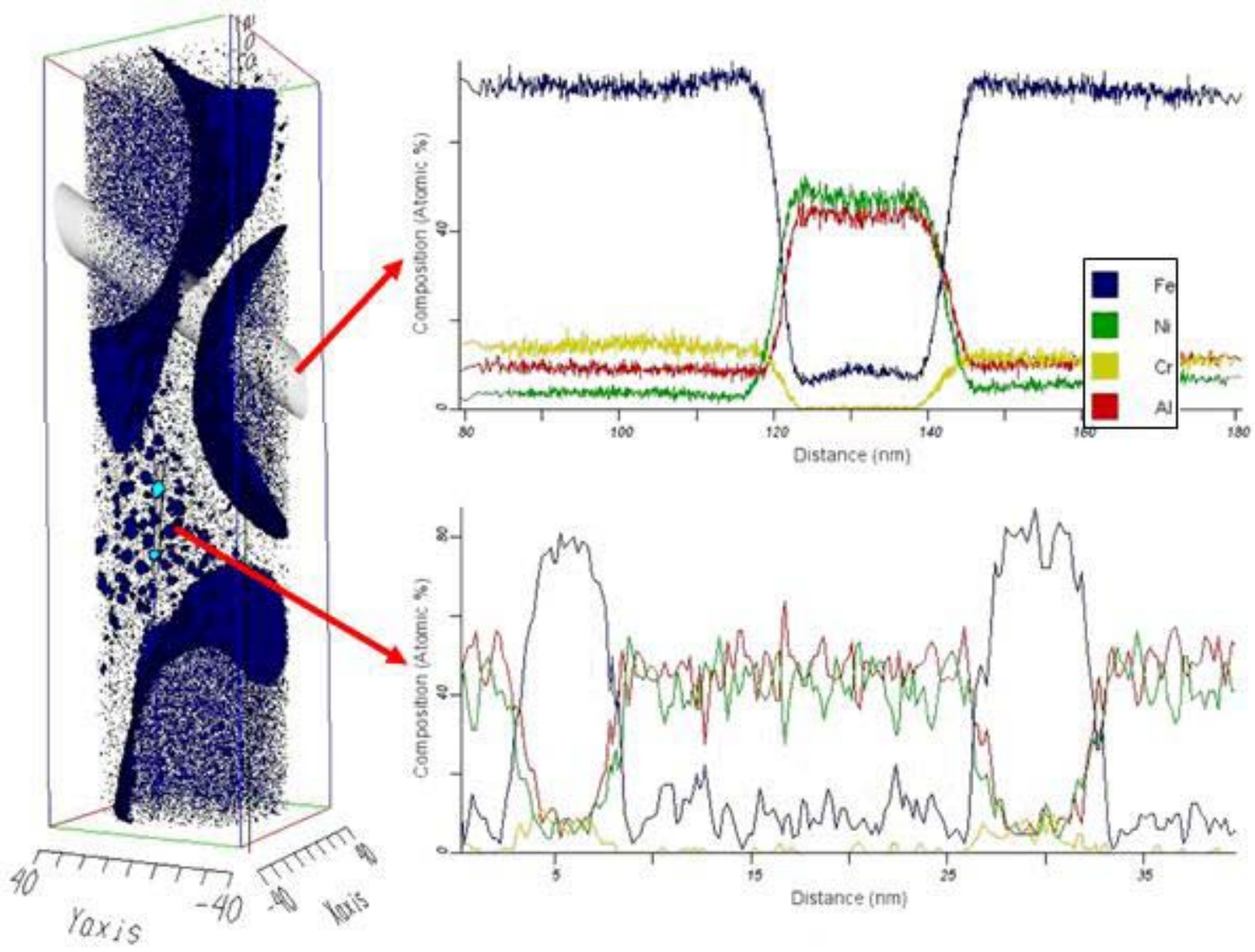

Fig. 2. LEAP atom map showing positions of Fe atoms as blue dots (left) and isoconcentration surfaces used to delineate the interfaces between the A2 (ferritic) and B2 $((\mathrm{Ni}, \mathrm{Fe}) \mathrm{Al})$ phases. The corresponding composition profiles through two different regions are shown at right. These results indicate that the nanoscale precipitates in the B2 $\mathrm{NiAl}$ phase are secondary Fe-rich precipitates of approximately the same composition as the primary A2 phase. 